\title{
Correction to: Evaluation of Different Oxidative Stress Parameters and Apoptosis in Human Cervical Cancer Cells Exposed to Rod and Spherical Shaped Zinc Oxide Nanoparticles
}

\section{Debalina Bhattacharya $^{1} \cdot$ Aritra Bhattacharyya $^{1} \cdot$ Parimal Karmakar $^{1}$}

\section{Published online: 20 August 2019}

(C) Springer Science+Business Media, LLC, part of Springer Nature 2019

\section{Correction to: BioNanoScience (186)}

https://doi.org/10.1007/s12668-015-0186-5

The original article unfortunately contains minor errors in Fig. 1B.

The incorrect Fig. 1B is shown below.

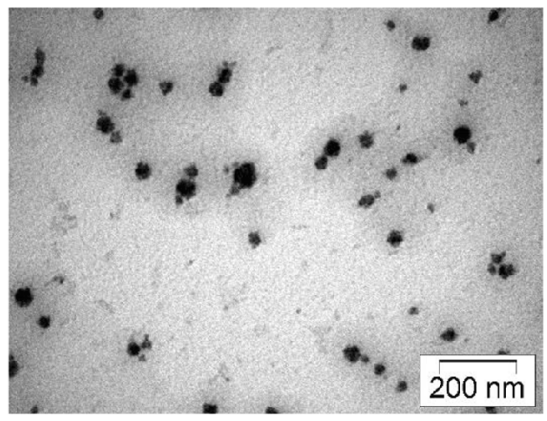

The correct Fig. 1B is shown below.

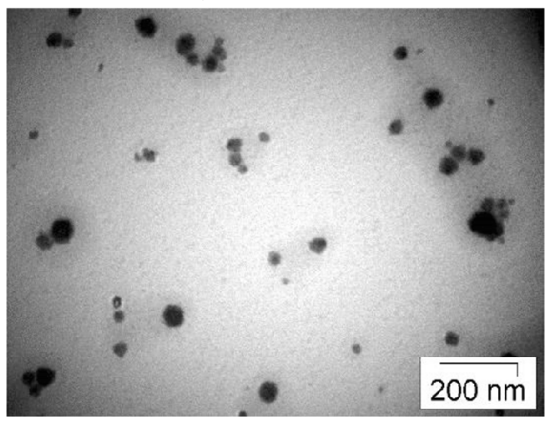

The online version of the original article can be found at https://oi.org/ $10.1007 / \mathrm{s} 12668-015-0186-5$

Parimal Karmakar

pkarmakar_28@yahoo.co.in

1 Department of Life Science and Biotechnology, Jadavpur University, Kolkata, India 